\title{
Gas-Phase Oxidation of Glycerol to Dihydroxyacetone over Tailored Iron Zeolites
}

\section{Journal Article}

Author(s):

Lari, Giacomo M.; Mondelli, Cecilia; Pérez-Ramírez, Javier

Publication date:

2015-03

Permanent link:

https://doi.org/10.3929/ethz-b-000100063

Rights / license:

In Copyright - Non-Commercial Use Permitted

Originally published in:

ACS Catalysis 5(3), https://doi.org/10.1021/cs5019056 


\section{Gas-phase Oxidation of Glycerol to}

\section{Dihydroxyacetone over Tailored Iron Zeolites}

Giacomo M. Lari, Cecilia Mondelli, and Javier Pérez-Ramírez*

Institute for Chemical and Bioengineering, Department of Chemistry and Applied Biosciences, ETH Zürich, Vladimir-Prelog-Weg 1, CH-8093 Zürich, Switzerland

KEYWORDS: glycerol valorization, oxidation, dihydroxyacetone, catalyst design, iron zeolites 


\section{ABSTRACT}

A novel chemocatalytic technology for the valorization of glycerol (GLY) is presented, where the continuous gas-phase oxidation to dihydroxyacetone (DHA) is accomplished over iron-containing zeolites in the presence of molecular oxygen. The catalyst design elucidated the impact of acidic properties and iron speciation on the performance. For this purpose, a series of catalysts displaying zeolitic or amorphous structure, different Brønsted and Lewisacid sites concentration and strength, and distinct iron species were synthesized, characterized by a multi-technique approach, and evaluated in a fixed-bed reactor. Fesilicalite prepared by isomorphous substitution of iron in the all-silica framework followed by steam activation at $873 \mathrm{~K}$ exhibits very mild acidity and highly-dispersed iron species in the form of isolated cations or small $\mathrm{FeO}_{x}$ clusters in extra-framework positions, leading to a stable DHA yield of ca. 90\%. Contrarily, impregnated or hydrothermally-prepared and steamed aluminum-containing catalysts feature strong acidity and/or a high iron clustering degree, promoting competitive dehydration or oxidation reactions and resulting in poor DHA yields. The optimal catalytic system identified largely outperforms the expensive noble metal-based catalysts reported to date and sets the basis for a process converting waste glycerol into DHA, a platform for the manufacture of polymers and fine chemicals. Interestingly, our study also uncovers the first oxidation reaction over iron zeolites in which molecular oxygen is a suitable oxidant and the typically applied $\mathrm{N}_{2} \mathrm{O}$ is ineffective. 


\section{INTRODUCTION}

In view of its low price and large availability, much research is being directed to the valorization of the huge amounts ( $\mathrm{ca} .3 \times 10^{6}$ tons in 2014) of glycerol (GLY) inevitably originating in the production of biodiesel. ${ }^{[1,2]}$ Among multiple conversion routes, its oxidation into dihydroxyacetone (DHA) is appealing. In fact, besides representing a widely used ingredient in the cosmetic industry, DHA has been demonstrated as a valuable monomer for the preparation of biocompatible and biodegradable polycarbonates and as a platform molecule of growing interest in biomass-to-chemicals value chains. ${ }^{[3,4]}$ In this respect, its conversion into lactic acid is particularly relevant due to the broadening applications of polylactide, as the demand of this commodity chemical has been estimated to reach $6 \times 10^{5}$ ton year ${ }^{-1}$ by $2020^{[4]}$ and, mainly due to the low productivity, the current enzymatic technology for its manufacture from sugars seems unable to sustain such a large market. ${ }^{[5]}$ In recent years, highly selective Lewis-acid tin-containing porous solids have been developed for the isomerization of DHA to lactic acid and alkyl lactates. ${ }^{[6-8]}$

GLY has been oxidized to DHA with high yields by means of bio-, homo-, or photocatalytic systems, including the bacterium gluconobacter oxydans $(90 \%),{ }^{[9]}$ a palladium complex applied in DMSO under aerobic conditions (69\%) or in a water-acetonitrile mixture with benzoquinone as the oxidant $(92 \%),{ }^{[10]}$ and $\mathrm{Bi}_{2} \mathrm{WO}_{6}$ under visible light irradiation $(87 \%) .{ }^{[11]}$ With regards to heterogeneous catalysis, a variety of materials based on gold, palladium, platinum, and alloys thereof have successfully accomplished the statistically favored and less demanding oxidation of the primary carbon atom of GLY, leading to glyceric acid. ${ }^{[12,13]}$ However, attempts to oxidize its secondary hydroxyl group using bimetallic Pt-Bi/C and Pd-Ag/C catalysts have attained DHA yields of only ca. $40 \% .{ }^{[14-16]}$ As common to the majority of chemocatalytic GLY conversion studies, liquid-phase conditions, 
mild temperatures, and low concentrations have been applied in these works to avoid degradation of the highly reactive substrate. Additionally, the possibility to perform the reactions in the industrially more attractive continuous operation rather than in batch mode has not been explored.

Iron-containing catalysts attracted our interest as a novel class of materials possibly suited for the oxidation of GLY to DHA due to the outstanding activity and selectivity of iron zeolites in $\mathrm{N}_{2} \mathrm{O}$-mediated reactions such as the oxidation of benzene to phenol and of propane to propene,$^{[17,18]}$ and the high activity of iron oxides in the dehydrogenation of alcohols under aerobic conditions. ${ }^{[19]}$ Aiming at working in the gas phase to ensure a higher productivity and avoid the possibly negative action of the aqueous medium on the stability of the active sites, ${ }^{[20]}$ we were confronted with specific catalyst design challenges. As summarized in Scheme 1, multiple competitive transformations could affect the efficiency of the process. The rather high temperature (>573 K) required to vaporize GLY makes it demanding to control the selectivity of the oxidation towards DHA rather than glyceraldehyde and can facilitate undesired dehydration reactions over acid sites of the support/matrix and/or the active phase. Acetol or acrolein have been indeed produced over materials displaying Lewis or Brønsted acidity, respectively. ${ }^{[21,22]}$ Additionally, both the oxidation and dehydration products formed can further transform. Thus, acrolein and, in particular, glyceraldehyde easily oxidize into acrylic and glyceric acid. The oxidation of acetol to pyruvaldehyde is also favorable due to the formation of a conjugated $\pi$-system between the ketonic and aldehydic carbonyl groups. Pyruvaldehyde can be alternatively generated by the dehydration of DHA over Brønsted- and Lewis-acid sites and can be readily oxidized to pyruvic acid. ${ }^{[23]}$ Further oxidative and/or acid-catalyzed degradation of secondary products is also expected, leading to $\mathrm{CO}_{2}$ and high molecular weight compounds and eventually to coke. ${ }^{[24]} \mathrm{CO}_{2}$ is also likely formed through oxidation of the carbonaceous species. 
Based on these premises, our catalyst design was based on the minimization of the acid character and increase of the selectivity of the redox iron site by precise tuning of the composition and structure of the material. Accordingly, aluminum-containing and aluminumfree iron-based MFI zeolites and amorphous materials were contrasted to study the effect of acidity. Furthermore, catalysts featuring iron sites with distinct degrees of clustering were generated by steaming of hydrothermally-synthesized iron-containing zeolites and by loading of different iron amounts on silicalite by dry impregnation to identify centers with optimal oxidation activity. In addition, we compared the use of $\mathrm{N}_{2} \mathrm{O}$ or $\mathrm{O}_{2}$ as the oxidant. After optimization of the reaction conditions over the best system, the condensate obtained from the oxidation of GLY was used to perform a liquid-phase isomerization over Sn-MFI zeolites to demonstrate a continuous cascade process for lactic acid production.

\section{EXPERIMENTAL}

2.1. Catalyst Preparation. Iron-containing catalysts were synthesized using different methods. An iron-containing MFI zeolite with nominal molar $\mathrm{Si} / \mathrm{Fe}=150$ and $\mathrm{Si} / \mathrm{Al}=40$ was prepared by hydrothermal synthesis following a recipe reported elsewhere. ${ }^{[25]}$ Briefly, tetraethylorthosilicate (10.90 g, Acros Organics, 98\%) was added to an aqueous solution of $\mathrm{NaOH}\left(10.4 \mathrm{~cm}^{3}, 1 \mathrm{M}\right)$ and tetrapropylammonium hydroxide $(2.65 \mathrm{~g}, \mathrm{ABCR}, 40 \%)$. After stirring for $2 \mathrm{~h}$ at room temperature, the mixture was slowly added to a solution of $\mathrm{Fe}\left(\mathrm{NO}_{3}\right)_{3} \cdot 9 \mathrm{H}_{2} \mathrm{O}(0.14 \mathrm{~g}$, Sigma-Aldrich, $98 \%)$ and $\mathrm{Al}\left(\mathrm{NO}_{3}\right)_{3} \cdot 9 \mathrm{H}_{2} \mathrm{O}(0.49 \mathrm{~g}$, Acros Organics, $99 \%)$ in a Teflon-lined stainless-steel autoclave $\left(150 \mathrm{~cm}^{3}\right)$ and heated at $448 \mathrm{~K}$ for 5 days. The solid formed was filtered, washed with deionized water, dried at $338 \mathrm{~K}$ for $16 \mathrm{~h}$, and calcined in static air at $823 \mathrm{~K}\left(5 \mathrm{~K} \mathrm{~min}^{-1}\right)$ for $5 \mathrm{~h}$ to remove the structure-directing agent. This sample was denoted as Na-FeZ. A part of it was converted into the protonic form by three consecutive ion exchanges in a $0.1 \mathrm{M}$ aqueous $\mathrm{NH}_{4} \mathrm{NO}_{3}$ solution $\left(6 \mathrm{~h}, 298 \mathrm{~K}, 100 \mathrm{~cm}^{3}\right.$ 
per gram of dried zeolite) followed by calcination under the conditions mentioned above. This sample was denoted as FeZ. An analogous protonic aluminum-free sample was prepared following the same protocol without addition of the aluminum source in the synthesis gel and was denoted as FeS. $2 \mathrm{~g}$ of these zeolites were subjected to steaming in a $30 \mathrm{vol} . \% \mathrm{H}_{2} \mathrm{O} / \mathrm{N}_{2}$ flow $\left(50 \mathrm{~cm}^{3} \mathrm{~min}^{-1}\right)$ at $773-1173 \mathrm{~K}\left(5 \mathrm{~K} \mathrm{~min}^{-1}\right)$ for $5 \mathrm{~h}$. The codes of the samples thus obtained were extended by an $s T$ suffix, where $T$ represents the steaming temperature (e.g., FeZ-s873). Additional iron-containing catalysts with a nominal 0.7 wt. $\% \mathrm{Fe}$ content (corresponding to a molar $\mathrm{Si} / \mathrm{Fe}=150$ ) were prepared by dry impregnation of $\mathrm{H}-\mathrm{ZSM}-5$ zeolite (molar $\mathrm{Si} / \mathrm{Al}=40$, Zeolyst International, CBV8014, denoted as Fe/Z40), silicalite (molar Si/Al = 1000, Tosoh Corporation, HSZ-8090H0A, denoted as Fe/Z1000), a selfprepared silicalite attained following the same hydrothermal synthesis procedure described above using only the silicon source for the preparation of the synthesis gel (denoted as $\mathrm{Fe} / \mathrm{S}$ ), $\mathrm{SiO}_{2}$ (Evonik, Aerosil 130), and $\mathrm{SiO}_{2}-\mathrm{Al}_{2} \mathrm{O}_{3}$ (Sigma-Aldrich, grade 135) with an aqueous solution of $\mathrm{Fe}\left(\mathrm{NO}_{3}\right)_{3} \cdot 9 \mathrm{H}_{2} \mathrm{O}$, followed by drying at $338 \mathrm{~K}$ for $16 \mathrm{~h}$ and calcination at $823 \mathrm{~K}$ $\left(5 \mathrm{~K} \mathrm{~min}^{-1}\right.$ ) for $5 \mathrm{~h}$. In the case of the $\mathrm{S}$ carrier, four additional catalysts with nominal iron loadings of $0.1,0.4,1.0$ and $1.5 \mathrm{wt} . \%$ were prepared by this method.

5 wt. $\% \mathrm{Pt} / \mathrm{Al}_{2} \mathrm{O}_{3}$ and 5 wt. $\% \mathrm{Pd} / \mathrm{Al}_{2} \mathrm{O}_{3}$ supplied by $\mathrm{BASF}$ were used as received. 0.8 wt.\% Au- 0.2 wt. $\% \mathrm{Cu} / \mathrm{SiO}_{2}$ was prepared following a reported procedure. ${ }^{[26]}$ Briefly, $1.7 \mathrm{~cm}^{3}$ of an aqueous solution of $\mathrm{HAuCl}_{4}(\mathrm{ABCR}, 99.9 \%)$ and $\mathrm{CuCl}_{2}$ (Sigma-Aldrich, $>99.9 \%$ ) were added to $1 \mathrm{~g}$ of silica, followed by $1.6 \mathrm{~cm}^{3}$ of aqueous ammonia (3 wt.\%). Reduction of the metals was achieved through the addition of $2.5 \mathrm{~cm}^{3}$ of a $0.13 \mathrm{M}$ aqueous $\mathrm{NaBH}_{4}$ solution (Sigma-Aldrich, >96\%) and stirring of the suspension at $333 \mathrm{~K}$ for $10 \mathrm{~min}$. The solid obtained was filtered, washed with $250 \mathrm{~cm}^{3}$ of deionized water, and dried at $338 \mathrm{~K}$ for $16 \mathrm{~h}$. 
2.2. Catalyst Characterization. The metal ( $\mathrm{Si}, \mathrm{Al}, \mathrm{Fe}$, and $\mathrm{Sn})$ content in the samples was determined by inductively coupled plasma optical emission spectroscopy (ICP-OES) using a Horiba Ultra 2 instrument equipped with a photomultiplier tube detector. The carbon content in the used catalysts was determined by thermo-gravimetric analysis (Mettler Toledo TGA/DSC1). Measurements were conducted in the $298-1173 \mathrm{~K}$ range $\left(10 \mathrm{~K} \mathrm{~min}^{-1}\right)$ and applying an air flow of $60 \mathrm{~cm}^{3} \mathrm{~min}^{-1}$. Powder X-ray diffraction (XRD) was performed using a PANalytical X'Pert PRO-MPD diffractometer. Data were acquired in the $3-60^{\circ} 2 \theta$ range with a step size of $0.05^{\circ}$ and a counting time of $8 \mathrm{~s}$ per step. $\mathrm{N}_{2}$ sorption at $77 \mathrm{~K}$ was conducted using a Quantachrome Quadrasorb-SI analyzer. Prior to the analyses, the samples were degassed in vacuum at $573 \mathrm{~K}$ for $3 \mathrm{~h}$. Transmission electron microscopy (TEM) was undertaken using a FEI Tecnai F30 microscope operated at $300 \mathrm{kV}$ (field emission gun). The samples were prepared by depositing a few droplets of the zeolite suspension in methanol onto a carbon-coated copper grid, followed by evaporation at room temperature. SEM was performed by using a Zeiss Gemini 1530 FEG microscope on Pt-coated samples ( $2 \mathrm{~nm}$ ). UVVis spectroscopy was carried out using a Varian Cary 4000 spectrometer equipped with a diffuse reflectance cell (Harrick). Spectra were collected in the 200-800 nm range with a scan rate of $150 \mathrm{~nm} \mathrm{~min}{ }^{-1}$. Fourier transform infrared (FTIR) spectroscopy studies of adsorbed pyridine were performed using a Bruker IFS66 spectrometer equipped with a liquid- $\mathrm{N}_{2}$ cooled mercury cadmium telluride (MCT) detector. Zeolite wafers $\left(\mathrm{ca} .1 \mathrm{~cm}^{2}, 20 \mathrm{mg}\right.$ ) were evacuated at reduced pressure for $4 \mathrm{~h}$ at $693 \mathrm{~K}$, cooled to room temperature, and saturated with pyridine vapors (Sigma Aldrich, >99\%). Thereafter, they were evacuated at room temperature $(15 \mathrm{~min})$ and $373 \mathrm{~K}(30 \mathrm{~min})$. Spectra were recorded accumulating 32 scans in the range of $1700-1300 \mathrm{~cm}^{-1}$ with a resolution of $4 \mathrm{~cm}^{-1}$. The concentrations of Brønsted- and Lewis-acid sites were calculated following a reported procedure. ${ }^{[27]}$ Diffuse Reflectance Infrared Fourier Transform (DRIFT) spectroscopy of adsorbed NO was conducted using a 
Bruker Vertex 70 spectrometer equipped with a liquid- $\mathrm{N}_{2}$ cooled MCT detector and a diffuse reflectance cell (Harrick). After degassing the sample at $573 \mathrm{~K}$ for $4 \mathrm{~h}$ under nitrogen flow and cooling down to $373 \mathrm{~K}$, diluted NO (PanGas, 5.02 vol.\% NO/He) was admitted and spectra were recorded accumulating 64 scans in the $2300-1700 \mathrm{~cm}^{-1}$ range with a resolution of $4 \mathrm{~cm}^{-1}$. Electronic paramagnetic resonance spectroscopy was performed at room temperature using a Bruker ElexSys E500 spectrometer in the 100 to $6000 \mathrm{G}$ range. The resonator background was measured and subtracted from each spectrum.

2.3. Catalytic Testing. The gas-phase oxidation of glycerol was studied at ambient pressure in a continuous-flow reactor setup (Scheme 2) comprising: (i) mass flow controllers for feeding $\mathrm{N}_{2}$ (PanGas, 99.999\%) and $\mathrm{N}_{2} \mathrm{O}$ (PanGas, 99.5\%) or $\mathrm{O}_{2}$ (PanGas, 99.9\%), (ii) a syringe pump for the injection of liquids, (iii) a tubular quartz micro-reactor (i.d. $=6 \mathrm{~mm}$ ) heated in an oven, (iv) a liquid-gas separator immersed in an ice bath, and (v) a gas bag. The catalyst $(0.1 \mathrm{~g}$, particle size $=0.2-0.4 \mathrm{~mm})$ was loaded into the reactor, which was then filled with 2-mm glass spheres in order to facilitate the evaporation of glycerol. The system was heated at the reaction temperature $(623 \mathrm{~K})$ in $\mathrm{N}_{2}$ flow and allowed to equilibrate for $30 \mathrm{~min}$. Thereafter, a gas mixture consisting of 3-9 vol.\% $\mathrm{O}_{2}$ in $\mathrm{N}_{2}\left(50-400 \mathrm{~cm}^{3} \mathrm{~min}^{-1}\right)$ was fed along with glycerol (Sigma-Aldrich, $>99.5 \%, 0.006-0.018 \mathrm{~cm}^{3} \mathrm{~min}^{-1}$ ). Liquid samples were periodically collected from the condenser and analyzed by high-performance liquid chromatography (HPLC) using a system (Merck LaChrome) equipped with a HPX-87H column kept at $308 \mathrm{~K}$ and $\mathrm{UV}-\mathrm{V}$ is and refractive index detectors. A $0.005 \mathrm{M} \mathrm{H}_{2} \mathrm{SO}_{4}$ aqueous solution flowing at $0.6 \mathrm{~cm}^{3} \mathrm{~min}^{-1}$ was used as the eluent. Dihydroxyacetone was quantified using a diode-array detector at $270 \mathrm{~nm}$. Calibration curves were measured using dihydroxyacetone (Merck), pyruvic acid (ABCR, 98\%), pyruvaldehyde (Acros Organics, 40\%), glycerol (Sigma-Aldrich, >90\%), glyceraldehyde (Sigma-Aldrich, >90\%), acetic acid (Acros Organics, >99.7\%), hydroxyacetone (Alfa Aesar, 95\%), acrylic acid (Acros 
Organics, 99.5\%), and acrolein (Fluka, >95\%) and using butanone as a standard. The latter was added to the reaction mixture prior to the analysis. The outlet gases collected in the gas bag were analyzed using a gas chromatograph (HP 5890) equipped with a gas sampling valve, a Restek-Shin Carbon ST 80/100 column, and a thermal conductivity detector. The conversion was calculated as the number of moles of glycerol reacted per mole of glycerol fed, the dihydroxyacetone selectivity as the number of moles of dihydroxyacetone formed per mole of glycerol reacted, and the dihydroxyacetone yield as the product between glycerol conversion and dihydroxyacetone selectivity. The carbon balance was calculated as the ratio between the moles of carbon in the liquid and gas products and moles of carbon fed. The experimental error, determined based on three repetitions of selected tests, was within $8 \%$. No glycerol conversion was observed performing blank runs and the low residence time allowed for negligible decomposition of the substrate on the reactor walls.

\section{RESULTS AND DISCUSSION}

3.1. Synthesis and Properties of the Iron-Containing Catalysts. Distinct sets of catalysts were prepared in order to study the effect of structure, acidity, and redox properties on the oxidation performance and to identify the optimal interplay of these parameters. To assess the impact of the structure, iron-containing MFI (alumino)silicates were generated by hydrothermal synthesis and by dry impregnation of amorphous (silica and silica-alumina) and crystalline (H-ZSM-5 with $\mathrm{Si} / \mathrm{Al}=40$ and silicalite) materials. An additional sample was prepared according to the latter method using a self-prepared hydrothermally-synthesized silicalite as a support, to rule out the influence of the iron impurities that are present in the commercial material (Table 1). The reason for selecting the MFI framework was twofold: $(i)$ it can be prepared in a wide range of $\mathrm{Si} / \mathrm{Al}$ ratios and (ii) iron can be incorporated into it effectively and extracted in a controlled manner by post-synthetic methods. 
In order to evaluate the role of acidity, the MFI zeolites produced by hydrothermal synthesis comprised an aluminum-free sample and an aluminum-containing material in both sodium and protonic forms. Furthermore, the protonic zeolites were subjected to steaming at variable temperature. This treatment has been demonstrated effective in displacing the heteroatoms from the framework and to typically lead to $\mathrm{FeO}_{x}$ oligonuclear species and small clusters, if performed under mild conditions, and to defined iron oxide nanoparticles, if conducted under harsher conditions. ${ }^{[28]}$ Accordingly, it not only served to modify the acidity of the ferrosilicate but also to vary the morphology and the redox properties of the iron sites. The elucidation of the latter effect was further addressed preparing a series of supported iron catalysts with variable iron loading (0.1-1.5 wt.\%) by dry impregnation of the self-prepared silicalite.

Elemental analysis (Tables 1) confirmed that the iron content in all of the samples was close to the nominal value and that did not change upon steam treatment of the hydrothermally-prepared catalysts. Porosity and surface area values for the latter fall in the range typical for MFI zeolites (Table 1). Upon steaming, a slight decrease in surface area and micropore volume was observed along with an increase in mesoporous surface. These evidences are consistent with a gradual migration of heteroatoms from the framework to extraframework positions. The textural properties of the commercial materials and of the selfprepared silicalite (Table 1) remained unaltered upon impregnation due to the low amount of iron loaded. X-ray diffraction (Figure 1a) evidenced the typical MFI pattern for all of the zeolites and indicated that the crystallinity was substantially retained even upon steaming at the highest temperature. As expected, amorphous samples showed broad reflections. No diffraction peaks attributed to iron-containing phases were observed, in line with the substantial integration of iron in the framework in the hydrothermally-synthesized solids or the low loading and small size of the species formed in the other systems. As visualized by 
SEM (Figure 2, left), hydrothermally-synthesized zeolites consisted of agglomerated crystals with a diameter of $c a .1 .5 \mu \mathrm{m}$ and their morphology was negligibly altered upon steaming. Infrared studies of adsorbed pyridine (Table 1) indicated that the concentration of Brønstedacid sites in $\mathrm{FeZ}$ and $\mathrm{Fe} / \mathrm{Z} 40$ is higher than in the case of $\mathrm{FeS}$ and $\mathrm{Fe} / \mathrm{S}$ catalysts, as anticipated from the additional presence of aluminum in the zeolite framework. All of these samples also exhibit Lewis-acid centers, in an inferior or equal amount compared to the Brønsted-acid sites for the aluminosilicates or FeS, respectively. In the case of the Fe/Z1000 and $\mathrm{Fe} / \mathrm{S}$ materials only acid sites with Lewis-acid character are present. The alterations in Brønsted and Lewis acidity upon steaming are in agreement with the extraction of aluminum and iron, which was more pronounced under the more severe conditions. As expected, the Brønsted acidity of Na-FeZ was very low.

UV-Vis spectroscopy (Figure 1b), EPR spectroscopy (Figure 1c), and DRIFT spectroscopy of adsorbed NO (Figure 1d) were further applied to elucidate the nature, placement, and degree of agglomeration of the iron centers. The UV-Vis spectra of FeS and FeZ display a main contribution below $350 \mathrm{~nm}$, which corroborates incorporation of iron into the MFI framework. The appearance of an additional broad signal above $350 \mathrm{~nm}$ for the steamed ferrosilicates indicates the partial displacement of iron from the framework and the formation of extraframework $\mathrm{FeO}_{x}$ clusters and iron oxide nanoparticles of variable size. As this spectral feature is less pronounced for FeS-s873 with respect to FeS-s1173, FeZ-s873, and FeZ-s1173, it can be suggested that iron redistribution led to smaller clusters in the first sample. This is in line with the fact that the presence of aluminum has been shown to facilitate iron extraction from the framework. ${ }^{[28]}$ The curves of all of the impregnated materials with iron loading of $c a .0 .7 \mathrm{wt} . \%$ exhibit a broad and multicomponent absorbance expanding up to $600 \mathrm{~nm}$, pointing to the coexistence of smaller and larger particles of iron oxide. The different relative contributions of the bands in the 180-350 and 350-550 nm 
regions in the UV-Vis spectra (Figure 3a) of Fe/S materials containing 0.1-1.5 wt.\% iron reveal the dominance of smaller metal particles in the low-loaded materials.

With respect to the EPR spectroscopic analysis, the resonances at $g^{\prime}=2$ and $g^{\prime}=4$ in the spectra of $\mathrm{FeZ}$ and FeS support the presence of isolated iron sites in framework position. Steaming at $873 \mathrm{~K}$ determined the strong sharpening of the feature at $g^{\prime}=2$, attributed to the superparamagnetic behavior of small iron oxide nanoparticles. ${ }^{[29]}$ Since the profile of this band is sharper in the spectrum of FeS-s873 compared to that of FeZ-s873, smaller nanoparticles are expected in the former catalyst. ${ }^{[2]}$ The samples treated at $1173 \mathrm{~K}$ produced spectra featuring broad bands of high intensity, typical of ferromagnetic properties and thus indicative of bigger iron oxide particles. These findings are in agreement with the UV-Vis spectroscopy results and are supported by the TEM analysis of the samples. The TEM micrographs (Figure 2, right) indeed visualize a highly dispersed iron phase in FeS and FeSs873 and larger iron aggregates in FeZ-s1173. For the impregnated samples, clear conclusions cannot be derived from the EPR spectroscopic data since the low intensity of the signals implies that the majority of iron species remains undetected. This could be attributed to the presence of $\mathrm{Fe}(\mathrm{II})$ species in a non-paramagnetic state or, more probably, to a antiferromagnetic arrangement of neighboring magnetic domains in the larger iron oxide particles formed. ${ }^{[30]}$

In the DRIFT spectra of FeS and FeZ after NO adsorption (Figure 1d), two bands centered at $c a .2130$ and $1880 \mathrm{~cm}^{-1}$ were detected. The former is attributed to $\mathrm{NO}^{+}$species formed at Brønsted-acidic sites ${ }^{[31]}$ and its greater intensity in the case of $\mathrm{FeZ}$ is in line with the higher Brønsted acidity determined by the presence of aluminum for this sample. The latter is assigned to mononitrosyl species bonded to divalent iron cations present in the stericallyhindered $\gamma$ positions of the zeolite, i.e., $\mathrm{Fe}^{2+}(\mathrm{NO}) .{ }^{[32]}$ The broader shape of this signal in the spectrum of $\mathrm{FeZ}$ compared to that of $\mathrm{FeS}$ is in agreement with previous reports. ${ }^{[33]} \mathrm{A}$ band 
located at $1818 \mathrm{~cm}^{-1}$, ascribed to dinitrosyl species in $\alpha$ position, i.e., $\mathrm{Fe}^{2+}(\mathrm{NO})_{2}$, was additionally observed in the case of the FeS sample. ${ }^{[32]}$ A feature at $c a .1770 \mathrm{~cm}^{-1}$, due to mononyitrosyl species formed on the same sites, usually accompanies this band. In our case, this signal was not observed likely due to the high concentration of NO (5 vol.\%) leading to the full saturation of the sites. ${ }^{[34]}$ The appearance of bands of NO adsorbed on the hydrothermally-prepared samples overall indicates that not all of the iron was present in these zeolites in form of fully coordinated $\mathrm{Fe}^{3+}$ framework species, but that extraframework sites of different nature were occupied by iron ions after calcination. The spectrum of FeZ-s873 evidences various bands between 1900 and $1850 \mathrm{~cm}^{-1}$ along with a signal at $1818 \mathrm{~cm}^{-1}$, indicating the redistribution of a part of the iron from framework positions to $\alpha$ and $\beta$ sites. Upon steaming at a higher temperature, the former reduced to a weak absorbance centered at $1880 \mathrm{~cm}^{-1}$, while the band at $1818 \mathrm{~cm}^{-1}$ retained its intensity. This suggests a further relocation of iron ions from $\beta$ and $\gamma$ framework positions to extraframework sites, where energetically more stable and NO-insensitive $\mathrm{Fe}_{2} \mathrm{O}_{3}$ species are formed, ${ }^{[35]}$ as demonstrated by the other characterization techniques. In the case of the aluminum-free samples, the spectrum of FeZ-s873 evidenced only moderate changes in the NO adsorption bands at 1870 and $1818 \mathrm{~cm}^{-1}$ compared to that of FeS. In contrast, the relative intensity of these signal was strongly altered upon steaming at $1173 \mathrm{~K}$. Effectively, the spectrum of FeS-s1173 closely resembles that of FeZ-s1173. The intensity of the band at $2130 \mathrm{~cm}^{-1}$ was significantly reduced upon steam treatment for both aluminum-containing and aluminum-free zeolites, in agreement with the depletion of Brønsted acidity shown in Table 1. In the case of the impregnated zeolites, NO adsorption bands were detected in the $1810-1850 \mathrm{~cm}^{-1}$ region, indicating that part of the iron is present in form of isolated sites. Specifically, while Fe/Z1000 almost exclusively produced a narrow mononitrosyl band at $1818 \mathrm{~cm}^{-1}$, a broad and multicomponent signal is evident in the spectrum of Fe/Z40. The latter seems to imply ${ }_{13}$ 
the existence of iron species at multiple locations in the zeolites and/or of iron sites influenced by the variable occurrence of aluminum in their proximity. The spectra of the $\mathrm{Fe} / \mathrm{S}$ catalyst series (Figure 3b) indicate that $\mathrm{Fe}^{2+}$ species in $\alpha$ position were formed only at low loading. In the case of the impregnated amorphous samples, no bands attributed to NO adsorption were observed, suggesting that iron was mostly present in form of $\mathrm{Fe}_{2} \mathrm{O}_{3}$ particles, in agreement with the UV-Vis spectroscopy data.

Overall, the characterization results for as-prepared and steamed FeS and FeZ samples are in substantial agreement with previous evidence. ${ }^{[28]}$ Still, significant displacement of iron from framework positions was observed for FeS upon steaming at moderate temperature $(873 \mathrm{~K})$, while literature data indicate that harsher conditions $(1173 \mathrm{~K})$ are required.

3.2. GLY Oxidation Performance of the Iron-Containing Catalysts. All of the catalysts were tested in the gas-phase oxidation of GLY at $623 \mathrm{~K}$ (Table 2). Impregnated amorphous catalysts yielded DHA with selectivities up to $53 \%$, while impregnated and hydrothermallyprepared zeolites reached DHA selectivities up to $72 \%$, evidencing the beneficial influence of a microporous crystalline structure on the catalyst performance. Interestingly, hardly any products arising from the oxidation of the primary hydroxyl group were detected. Since iron atoms present in framework positions are not expected to have oxidation ability, being fully coordinated, the redox activity of hydrothermally-prepared samples was related to the presence of uncoordinated atoms in extraframework positions, identified by DRIFT spectroscopy of adsorbed NO (Figure 1d).

Considering the better-performing zeolite-based samples, it was clear that acidity had a major negative contribution on the selectivity pattern of condensable products. Thus, dehydration pathways leading to pyruvaldehyde and pyruvic acid were more easily triggered on the more Brønsted- and Lewis-acidic FeZ compared to FeS. Additionally, a considerably improved DHA selectivity was observed when the former solid was applied in its sodium 
form and a diminished production of acrolein, catalyzed by strong Brønsted-acid sites, and acrylic acid was found for the steamed zeolites (combined selectivity of 6 and $1 \%$ for FeZ and FeZ-s1173 and 2 and 0\% for FeS and FeS-s1173, respectively).

Besides for its undesired catalytic effect for dehydration reactions, acidity also significantly favored coke formation. In particular, a direct relationship was found between the concentration of Brønsted-acid sites in the impregnated samples and hydrothermallysynthesized zeolites prior to and after steaming and the amount of coke after reaction, as determined by thermogravimetric analysis (Figure 4). Fouling was particularly pronounced in the case of Fe/Z40. A full blockage of the active sites is a feasible explanation of the complete inactivity of this material in transforming GLY. Analogously, extremely rapid and extensive coking has been observed over $\mathrm{H}-\mathrm{ZSM}-5$ zeolites with $\mathrm{Si} / \mathrm{Al}$ ratios between 25 and 150 applied in the gas-phase dehydration of GLY to acrolein. ${ }^{[36]}$

As the reduction of acidity upon steaming of FeZ was expected to lead to higher DHA selectivities but only minor changes were observed in this respect (Figure 5a), it was assumed that the favorable decrease in acidity (Table 1) was counterbalanced by the negative impact of increasing the clustering degree of the iron sites (Figure 1). This interpretation is supported by the nature of the main side products generated by these samples. Coke and $\mathrm{CO}_{2}$ were formed on the Brønsted-acid sites of the non-steamed catalyst and pyruvaldehyde and pyruvic acid were produced over the unselective big iron oxide particles of the treated samples. Also in the case of hydrothermally-synthesized FeS, the steam treatment determined a suppression of acidity and morphological alterations of the iron sites. Nevertheless, in contrast to the aluminum-containing samples and due to the originally lower acidity and the less pronounced aggregation of iron upon low-temperature steaming, the catalytic properties were initially enhanced (Figure 5b) and then depleted. Optimal acid and redox properties were achieved upon steaming at intermediate temperature $(873 \mathrm{~K})$, which reduced the 
formation of $\mathrm{CO}_{2}$ and led to an outstanding DHA selectivity of $88 \%$. Upon augmenting the severity of the steam treatment, increasing pyruvaldehyde and pyruvic acid selectivities were observed as for the FeZ steamed samples. The superior oxidation behavior of small iron clusters was also evident when comparing the performance of the supported materials prepared by impregnation of commercial (Fe/Z1000) or self-prepared (Fe/S) silicalite $(69 \%$ and $40 \%$ selectivity to DHA, respectively, Table 2). Indeed, the iron impurities in silicalite are mostly present as isolated framework or extraframework species, as confirmed by a DRIFT spectroscopy of adsorbed NO (not shown), while the iron species formed upon impregnation of silicalite comprised particles with a broad size distribution (Figure 2). The negative role of large iron particles was further substantiated by the analysis of the performance of $\mathrm{Fe} / \mathrm{S}$ samples loaded with different amounts of iron (0.1-1.5 wt.\%, Figure 5c). The curves obtained upon plotting the selectivity to DHA and the cumulative selectivity to pyruvaldehyde and pyruvic acid against the sum of the intensity of the UV-Vis bands (Figure 5d) located at $350 \mathrm{~nm}$ and $550 \mathrm{~nm}$ divided by that of the band at $230 \mathrm{~nm}$ (i.e., ratio of medium-large iron aggregates to isolated iron sites and small clusters) show an opposite trend, highlighting the higher selective oxidation ability of samples featuring a larger proportion of non-agglomerated iron species.

$\mathrm{FeS}$ and $\mathrm{FeZ}$ and their steamed forms have been widely reported to catalyze the selective oxidation of benzene and aliphatic hydrocarbons in the presence of $\mathrm{N}_{2} \mathrm{O}$. Accordingly, their ability to activate nitrous oxide for the oxidation of GLY was tested. All the aluminum-free samples showed no activity, while oxidation and dehydration product were detected with aluminum-containing materials (Table 2). The role of $\mathrm{N}_{2} \mathrm{O}$ in the latter transformations was ruled out by the identical product distributions obtained performing the reaction in inert atmosphere. This evidence points to the fact that the iron species also catalyze non-oxidative dehydrogenation, although this pathway is activated only in the co-presence of strong 
acidity. It is speculated that the inefficacy of $\mathrm{N}_{2} \mathrm{O}$ as oxidant descends from the occurrence of a different reaction mechanism for GLY compared to hydrocarbon oxidation (i.e., hydrogen is released from the former and is not in the latter case). An in-depth understanding of this interesting finding lies beyond the scope of this study, but certainly deserves further investigation.

Reaction parameters, i.e., $\mathrm{O}_{2} / \mathrm{GLY}$ ratio and contact time, were optimized using the best catalyst, FeS-s873. With respect to the first parameter (Figure 6a), large oxygen excess led to a selectivity drop due to formation of high amounts of $\mathrm{CO}_{2}$, while lower $\mathrm{O}_{2} / \mathrm{GLY}$ ratios resulted in a loss of activity due to pronounced coke deposition $\left(0 \mathrm{wt} . \%\right.$ at $\mathrm{O}_{2} / \mathrm{GLY}=2.5$ to 5.3 wt. $\%$ at $\mathrm{O}_{2} / \mathrm{GLY}=1.7$ ). Concerning the second variable (Figure 6b), mass transport limitations were observed at the highest flow rate, while the lowest flow favored coking of the catalyst and total oxidation reactions to $\mathrm{CO}_{2}$. Still, a rather high gas-hourly space velocity $(G H S V)$ was required to maximize the efficiency of the process. This seems to trace back to the minimization of dehydration reactions under these conditions. Indeed, upon feeding a 60 wt.\% DHA aqueous solution over the catalyst, pyruvaldehyde was formed with a yield of $40 \%$ at $G H S V=20000 \mathrm{~h}^{-1}$ while of only $16 \%$ at $G H S V=50000 \mathrm{~h}^{-1}$.

Finally, the stability of FeS-s873 was tested in a 32-h run (Figure 6c). The activity level was unaltered over the screened period and the DHA selectivity only slightly decreased due to a growing formation of pyruvaldehyde. The latter evidence suggests that iron sintering might take place to a little extent with time on stream. These results demonstrate the potential of iron zeolites for a future industrial application.

3.3. Towards a Glycerol-to-Lactic Acid Process. Recently, a few works have targeted to produce lactic acid or methyl lactate from GLY performing the oxidation of the triol and the isomerization of DHA in one pot. Bifunctional noble metal-containing zeolites such as $\mathrm{Pt} / \mathrm{Sn}$ $\mathrm{MFI}^{[37]}$ in water and $\mathrm{Au} / \mathrm{USY}^{[38]}$ in methanol have displayed high activity and selectivity 
(lactic acid and methyl lactate yields of 72 and $73 \%$, respectively). $\mathrm{Au} / \mathrm{CeO}_{2}$ in basic media has shown even slightly superior performance (lactic acid yield of $80 \%$ ). ${ }^{[39]}$ In spite of the promising catalytic results, poor recyclability of the heterogeneous solid and the use of homogeneous basic additives represent drawbacks for a large-scale application of some of these systems. Furthermore, no attempt was made to show the suitability of these catalysts for the widely preferred continuous-flow rather than batch operation.

The development of a robust catalytic technology for GLY oxidation to DHA allowed us to focus on an alternative two-step process in which the gas-phase production of the intermediate ketone over FeS-s873 is coupled to its isomerization in the liquid phase over a state-of-the-art Lewis-acid catalyst. One such material is hydrothermally-synthesized tincontaining MFI zeolite, which has been recently demonstrated to efficiently convert DHA in methanol in a continuous-flow fixed-bed reactor. ${ }^{[6]}$ The concept of a cascade process appears appealing because the biocatalytic oxidation of GLY followed by the batch chemocatalytic isomerization of DHA in water or in methanol over the same Sn-containing zeolite has been shown to represent an industrially viable technology to produce lactic acid, being more sustainable and economically much more attractive than the conventional sugar fermentation route. ${ }^{[6]}$ Our combined system is expected to further improve this scenario because of the continuous operation and the higher productivity of the iron-containing catalyst compared to the gluconobacter oxydans. An additional gain could be achieved if the DHA isomerization step could be performed without a prior energy-intensive removal of water from the DHA stream obtained by condensation at the reactor outlet after the oxidation step (i.e., an aqueous mixture containing up to 76 wt.\% DHA). Accordingly, a continuous-flow DHA isomerization test was performed over Sn-MFI using the unpurified solution simply diluted with methanol. The evolution of the methyl lactate yield with time on stream (not shown) virtually coincides 
with that obtained from a pure DHA methanolic solution, ${ }^{[6]}$ indicating that water has a negligible effect and the cascade process can be simplified.

\section{CONCLUSIONS}

Iron-containing catalysts were herein evaluated for the selective gas-phase oxidation of glycerol to dihydroxyacetone. Iron-containing silicalite prepared by hydrothermal synthesis followed by steaming under mild conditions demonstrated highly active, selective, and stable for the oxidation of the triol in the presence of oxygen, greatly surpassing other iron-based amorphous and crystalline (alumino)silicates generated via dry impregnation. Its superiority stemmed from the optimal tuning between structure, acidity, and morphology of the iron sites. In particular, this material features a very low acidity, which limits the extent of dehydration by-reactions, and iron sites mostly present as small and well-dispersed $\mathrm{FeO}_{x}$ clusters in extraframework position, which display enhanced selective oxidation ability. Overall, this system largely outperforms state-of-the-art catalysts based on noble metals and stands as an attractive technology to produce a relevant biobased chemical intermediate. It is worth noting that our work introduces the first application of iron zeolites in oxidation catalysis in which molecular oxygen is a suitable oxidant while $\mathrm{N}_{2} \mathrm{O}$ is ineffective.

\section{AUTHOR INFORMATION}

\section{Corresponding Author}

*Address: Institute for Chemical and Bioengineering, Department of Chemistry and Applied Biosciences, ETH Zurich, Vladimir-Prelog-Weg 1, CH-8093, Zurich, Switzerland. Phone: +41-44-633-7120. E-mail: jpr@ chem.ethz.ch. 


\section{Author Contributions}

The manuscript was written through contributions of all authors. All authors have given approval to the final version of the manuscript.

\section{ACKNOWLEDGMENTS}

This work was supported by the Swiss National Science Foundation (Project Number 200021-140496). Dr. S. Mitchell, Ms. N.-L. Michels, Dr. M. Yulikov, and Dr. D. Ferri are respectively acknowledged for their help with TEM and SEM analyses and EPR and UV-Vis spectroscopic measurements. The electron microscopy center of the ETH Zurich (ScopeM) is acknowledged for the use of their facility.

\section{REFERENCES}

(1) Pagliaro, M.; Ciriminna, R.; Kimura, H.; Rossi, M.; Della Pina, C. Angew. Chem., Int. Ed. 2007, 46, 4434-4440.

(2) OECD/FAO, OECD-FAO Agricultural Outlook 2014, OECD Publishing, doi: 10.1787/agr_outlook-2014-6-en.

(3) Zelikin, A. N.; Zawaneh, P. N.; Putnam, D. Biomacromolecules 2006, 7, 3239-3244.

(4) Dusselier, M.; Van Wouwe, P.; Dewaele, A.; Makshina, E.; Sels, B. F. Energy Environ. Sci. 2013, 6, 1415-1442.

(5) Cui, F.; Li, Y.; Wan, C. Bioresour. Technol. 2011, 102, 1831-1836.

(6) Lew, C. M.; Rajabbeigi, N.; Tsapatis, M. Microporous Mesoporous Mater. 2012, 153, $55-58$.

(7) Moliner, M. Dalton Trans. 2014, 43, 4197-4208.

(8) Morales, M.; Dapsens, P. Y.; Giovinazzo, I.; Witte, J.; Mondelli, C.; 
Papadokonstantakis, S.; Hungerbühler, K.; Pérez-Ramírez, J. Energy Environ. Sci. 2014, doi: 10.1039/C4EE03352C.

(9) Hekmat, D.; Bauer, R.; Fricke, J. Bioprocess Biosyst. Eng. 2003, 26, 109-116.

(10) Painter, R. M.; Pearson, D. M.; Waymouth, R. M. Angew. Chem., Int. Ed. 2010, 49, 9456-9459.

(11) Zhang, Y.; Zhang, N.; Tang, Z.-R.; Xu, Y.-J. Chem. Sci. 2013, 4, 1820-1824.

(12) Carrettin, S.; McMorn, P.; Johnston, P.; Griffin, K.; Hutchings, G. J. Chem. Commun. 2002, 696-697.

(13) Villa, A.; Campione, C.; Prati, L. Catal. Lett. 2007, 115, 133-136.

(14) Kimura, H.; Tsuto, K.; Wakisaka, T.; Kazumi, Y.; Inaya, Y. Appl. Catal., A 1993, 96, 217-228.

(15) Garcia, R.; Besson, M.; Gallezot, P. Appl. Catal., A 1995, 127, 165-176.

(16) Hirasawa, S.; Nakagawa, Y.; Tomishige, K. Catal. Sci. Technol. 2012, 2, 1150-1152.

(17) Panov, G. I.; Sheveleva, G. A.; Kharitonov, A. S.; Romannikov, V. N.; Vostrikova, L. A. Appl. Catal., A 1992, 82, 31-36.

(18) Bulánek, R.; Wichterlová, B.; Novoveská, K.; Kreibich, V. Appl. Catal., A 2004, 264, $13-22$.

(19) Wang, Y.; Davis, B. H. Appl. Catal., A 1999, 180, 277-285.

(20) Pérez-Ramírez, J.; Kapteijn, F.; Mul, G.; Moulijn, J. A. Chem. Commun. 2001, 693694.

(21) Katryniok, B.; Paul, S.; Dumeignil, F. ACS Catal. 2013, 3, 1819-1834.

(22) Chai, S.-H.; Wang, H.-P.; Liang, Y.; Xu, B.-Q. Green Chem. 2007, 9, 1130-1136.

(23) West, R. M.; Holm, M. S.; Saravanamurugan, S.; Xiong, J.; Beversdorf, Z.; Taarning, E.; Christensen, C. H. J. Catal. 2010, 269, 122-130. 
(24) Katryniok, B.; Paul S.; Capron, M.; Lancelot, C.; Bellièr-Baca, V; Rey, P.; Dumeignil, F. Green Chem. 2010, 12, 1922-1925.

(25) Ribera, A.; Arends, I. W. C. E.; de Vries, S.; Pérez-Ramírez, J.; Sheldon, R. A. J. Catal. 2000, 195, 287-297.

(26) Biella, S.; Rossi, M. Chem. Commun. 2003, 378-379.

(27) Emeis, C. A. J. Catal. 1993, 141, 347-354.

(28) Pérez-Ramírez, J. J. Catal. 2004, 227, 512-522.

(29) Yulikov, M. M.; Abornev, I. S.; Mart'yanov, O. N.; Yudanov, V. F.; Isupov, V. P.; Chupakhina, L. E.; Tarasov, K. A.; Mitrofanova, R. P. Kinet. Catal. 2004, 45, 735-738.

(30) Yafet, Y.; Kittel, C. Phys. Rev. 1952, 87, 290-294.

(31) Hadjiivanov, H.; Knözinger, H.; Tsyntsarski, B.; Dimitrov, L. Catal. Lett. 1999,62, 3540.

(32) Segawa, K.; Chen, Y.; Kubsh, J. E.; Delgass, W. N.; Dumesic, J. A.; Hall, W. K. J. Catal. 1982, 76, 112-132.

(33) Mul, G.; Pérez-Ramírez, J.; Kapteijn, F.; Moulijn, J. A. Catal. Lett. 2002, 80, 129-138.

(34) Krishna, K.; Seijger, G. B. F.; van den Bleek, C. M.; Makkee, M.; Mul, G.; Calis, H. P. A. Catal. Lett. 2003, 86, 121-132.

(35) Chen, H.-Y.; El-Malki, El-M.; Wang, X.; van Santen, R. A.; Sachtler, W. M. H. J. Mol. Catal. A: Chem. 2000, 162, 159-174.

(36) Kim, Y. T.; Jung, K.-D.; Park, E. D. Microporous Mesoporous Mater. 2010, 131, 2836.

(37) Cho, H. J.; Chang, C.-C.; Fan, W. Green Chem. 2014, 16, 3428-3433.

(38) Purushothaman, R. K. P.; van Haveren, J.; Melián-Cabrera, I.; van Eck, E. R. H.; Heeres, H. J. ChemSusChem 2014, 7, 1140-1147. 
(39) Purushothaman, R. K. P.; van Haveren, J.; van Es, D. S.; Melián-Cabrera, I.; Meeldijk, J. D.; Heeres, H. J. Appl. Catal., B 2014, 147, 92-100. 
Table 1. Characterization data of the zeolite samples.

\begin{tabular}{llllllll}
\hline Sample & $\begin{array}{l}\mathrm{Si} / \mathrm{Al}^{a} \\
\left(\mathrm{~mol} \mathrm{~mol}^{-1}\right)\end{array}$ & $\begin{array}{l}\mathrm{Fe}^{a} \\
(\mathrm{wt} . \%)\end{array}$ & $\begin{array}{l}V_{\text {pore }^{b}} \\
\left(\mathrm{~cm}^{3} \mathrm{~g}^{-1}\right)\end{array}$ & $\begin{array}{l}V_{\text {micro }^{c}} \\
\left(\mathrm{~cm}^{3} \mathrm{~g}^{-1}\right)\end{array}$ & $\begin{array}{l}S_{\mathrm{BET}}{ }^{d} \\
\left(\mathrm{~m}^{2} \mathrm{~g}^{-1}\right)\end{array}$ & $\begin{array}{l}c_{\text {Brønsted }}{ }^{e} \\
\left(\mu \mathrm{mol} \mathrm{g}^{-1}\right)\end{array}$ & $\begin{array}{l}c_{\text {Lewis }}{ }^{e} \\
\left(\mu \mathrm{mol} \mathrm{g}^{-1}\right)\end{array}$ \\
\hline $\mathrm{Z} 40$ & 43 & 0.05 & 0.26 & 0.16 & 453 & 142 & 20 \\
$\mathrm{~S}$ & $\infty$ & 0.00 & 0.19 & 0.15 & 384 & 0 & 0 \\
$\mathrm{FeZ}$ & 34 & 0.68 & 0.20 & 0.15 & 401 & 233 & 39 \\
$\mathrm{Na}-\mathrm{FeZ}$ & 35 & 0.63 & 0.23 & 0.15 & 409 & 37 & 45 \\
$\mathrm{FeZ}-\mathrm{s} 873$ & 34 & 0.67 & 0.21 & 0.14 & 376 & 73 & 23 \\
$\mathrm{FeZ}-\mathrm{s} 1173$ & 34 & 0.67 & 0.22 & 0.13 & 352 & 0 & 0 \\
$\mathrm{FeS}$ & $\infty$ & 0.78 & 0.22 & 0.16 & 404 & 47 & 49 \\
$\mathrm{FeS}-\mathrm{s} 873$ & $\infty$ & 0.78 & 0.23 & 0.16 & 424 & 10 & 57 \\
$\mathrm{FeS}-\mathrm{s} 1173$ & $\infty$ & 0.77 & 0.22 & 0.12 & 331 & 0 & 0 \\
$\mathrm{Fe} / \mathrm{Z} 40$ & 44 & 0.29 & 0.25 & 0.15 & 436 & 146 & 96 \\
$\mathrm{Fe} / \mathrm{Z} 1000$ & 1000 & 0.54 & 0.20 & 0.15 & 400 & 0 & 221 \\
$\mathrm{Fe} / \mathrm{S}$ & $\infty$ & 0.67 & 0.20 & 0.13 & 381 & 0 & 182 \\
\hline
\end{tabular}

${ }^{a}$ ICP-OES. ${ }^{b}$ Volume adsorbed at $p / p_{0}=0.99 .{ }^{c} t$-plot method. ${ }^{d}$ BET method. ${ }^{e}$ FTIR spectroscopy of adsorbed pyridine. 
Table 2. Steady-state performance of selected catalysts in the continuous gas-phase oxidation of glycerol. ${ }^{a}$

\begin{tabular}{llllllllll}
\hline Catalyst & Oxidant & $\begin{array}{l}X_{\mathrm{GLY}} \\
(\%)\end{array}$ & $\begin{array}{l}S_{\mathrm{DHA}} \\
(\%)\end{array}$ & $\begin{array}{l}S_{\mathrm{Ac}} \\
(\%)\end{array}$ & $\begin{array}{l}S_{\mathrm{PA}} \\
(\%)\end{array}$ & $\begin{array}{l}S_{\mathrm{PAc}} \\
(\%)\end{array}$ & $\begin{array}{l}S_{\text {Other }} \\
(\%)\end{array}$ & $\begin{array}{l}S_{\mathrm{CO} 2} \\
(\%)\end{array}$ & $\begin{array}{l}\mathrm{C}_{\text {balance }} \\
(\%)\end{array}$ \\
\hline $\mathrm{Fe} / \mathrm{SiO}_{2}$ & $\mathrm{O}_{2}$ & 99 & 53 & 0 & 9 & 22 & 3 & 14 & 86 \\
$\mathrm{Fe} / \mathrm{SiO}_{2}-\mathrm{Al}_{2} \mathrm{O}_{3}$ & $\mathrm{O}_{2}$ & 99 & 42 & 1 & 0 & 0 & 28 & 30 & 87 \\
$\mathrm{Fe} / \mathrm{Z}^{2} 000$ & $\mathrm{O}_{2}$ & 99 & 69 & 1 & 2 & 3 & 10 & 15 & 101 \\
$\mathrm{Fe} / \mathrm{Z40}$ & $\mathrm{O}_{2}$ & 0 & - & - & - & - & - & - & 84 \\
$\mathrm{Fe} / \mathrm{S}$ & $\mathrm{O}_{2}$ & 37 & 40 & 2 & 30 & 18 & 1 & 12 & 94 \\
$\mathrm{FeS}$ & $\mathrm{O}_{2}$ & 99 & 72 & 2 & 2 & 1 & 1 & 15 & 92 \\
$\mathrm{FeZ}$ & $\mathrm{O}_{2}$ & 85 & 40 & 4 & 8 & 30 & 11 & 20 & 89 \\
$\mathrm{Na}-\mathrm{FeZ}$ & $\mathrm{O}_{2}$ & 80 & 60 & 4 & 2 & 15 & 5 & 12 & 102 \\
$\mathrm{AuCu} / \mathrm{SiO}_{2}$ & $\mathrm{O}_{2}$ & 12 & 36 & 0 & 52 & 5 & 6 & & 95 \\
$\mathrm{Pt} / \mathrm{Al}{ }_{2} \mathrm{O}_{3}$ & $\mathrm{O}_{2}$ & 92 & 0 & 84 & 13 & 0 & 2 & & 88 \\
$\mathrm{Pd} / \mathrm{Al}_{2} \mathrm{O}_{3}$ & $\mathrm{O}_{2}$ & 7 & 0 & 7 & 76 & 0 & 16 & & 89 \\
$\mathrm{Fe} / \mathrm{SiO}_{2}$ & $\mathrm{~N}_{2} \mathrm{O}$ & 0 & - & - & - & - & - & - & 99 \\
$\mathrm{Fe} / \mathrm{SiO}_{2}-\mathrm{Al}_{2} \mathrm{O}_{3}$ & $\mathrm{~N}_{2} \mathrm{O}$ & 42 & 0 & 65 & 29 & 1 & 5 & 0 & 96 \\
$\mathrm{FeS}-\mathrm{s} 873$ & $\mathrm{~N}_{2} \mathrm{O}$ & 0 & - & - & - & - & - & - & 98 \\
$\mathrm{FeZ}-\mathrm{s} 873^{\mathrm{G}}$ & $\mathrm{N}_{2} \mathrm{O}$ & 59 & 28 & 42 & 38 & 20 & 4 & 0 & 89 \\
\hline
\end{tabular}

${ }^{a}$ GLY: glycerol, DHA: dihydroxyacetone, Ac: acetol, PA: pyruvaldehyde, PAc: pyruvic acid, 'Other' includes acetaldehyde, acetic acid, acrolein, and acrylic acid. $T=623 \mathrm{~K}$, $\mathrm{O}_{2} / \mathrm{GLY}=3.5, \mathrm{GHSV}=35000 \mathrm{~h}^{-1}$. Samples were collected between 1 and $2 \mathrm{~h}$ on stream. 


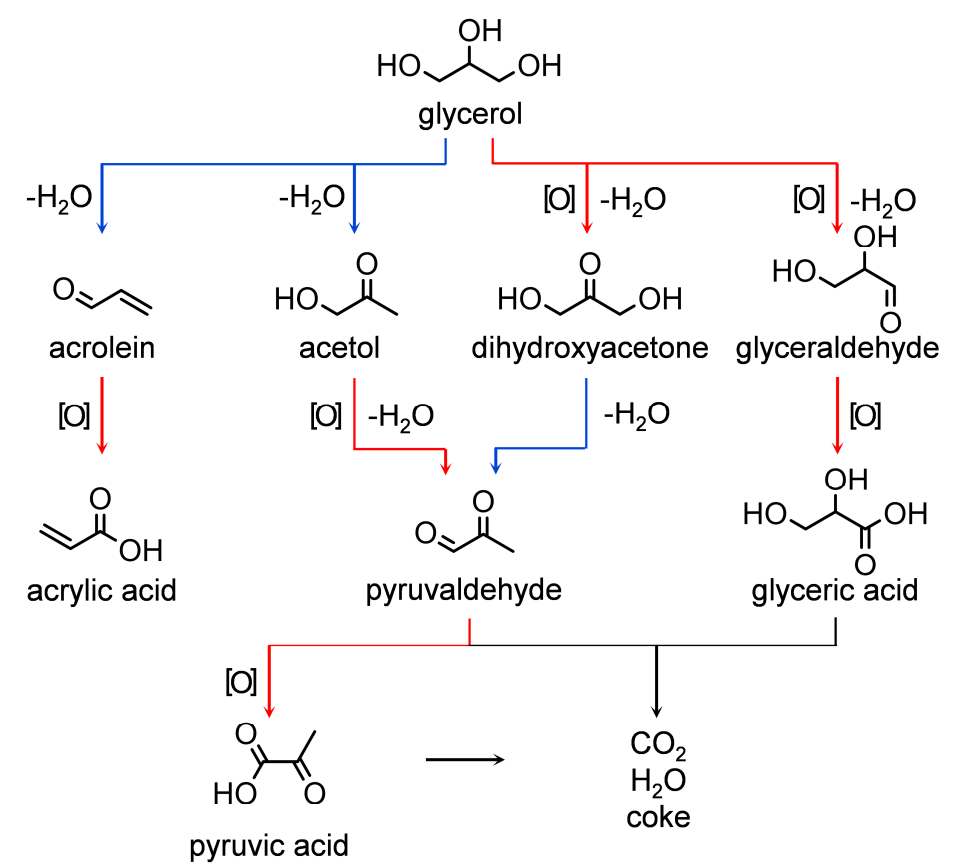

Scheme 1. Pathways of glycerol conversion based on oxidation (red) and dehydration (blue) reactions. 


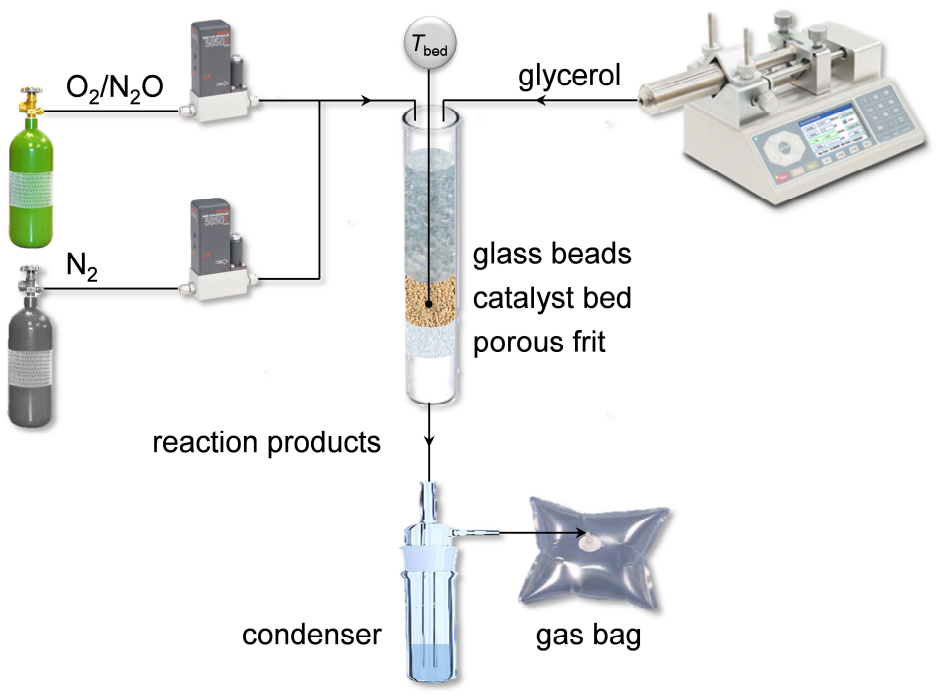

Scheme 2. Setup used for the continuous gas-phase oxidation of glycerol. 

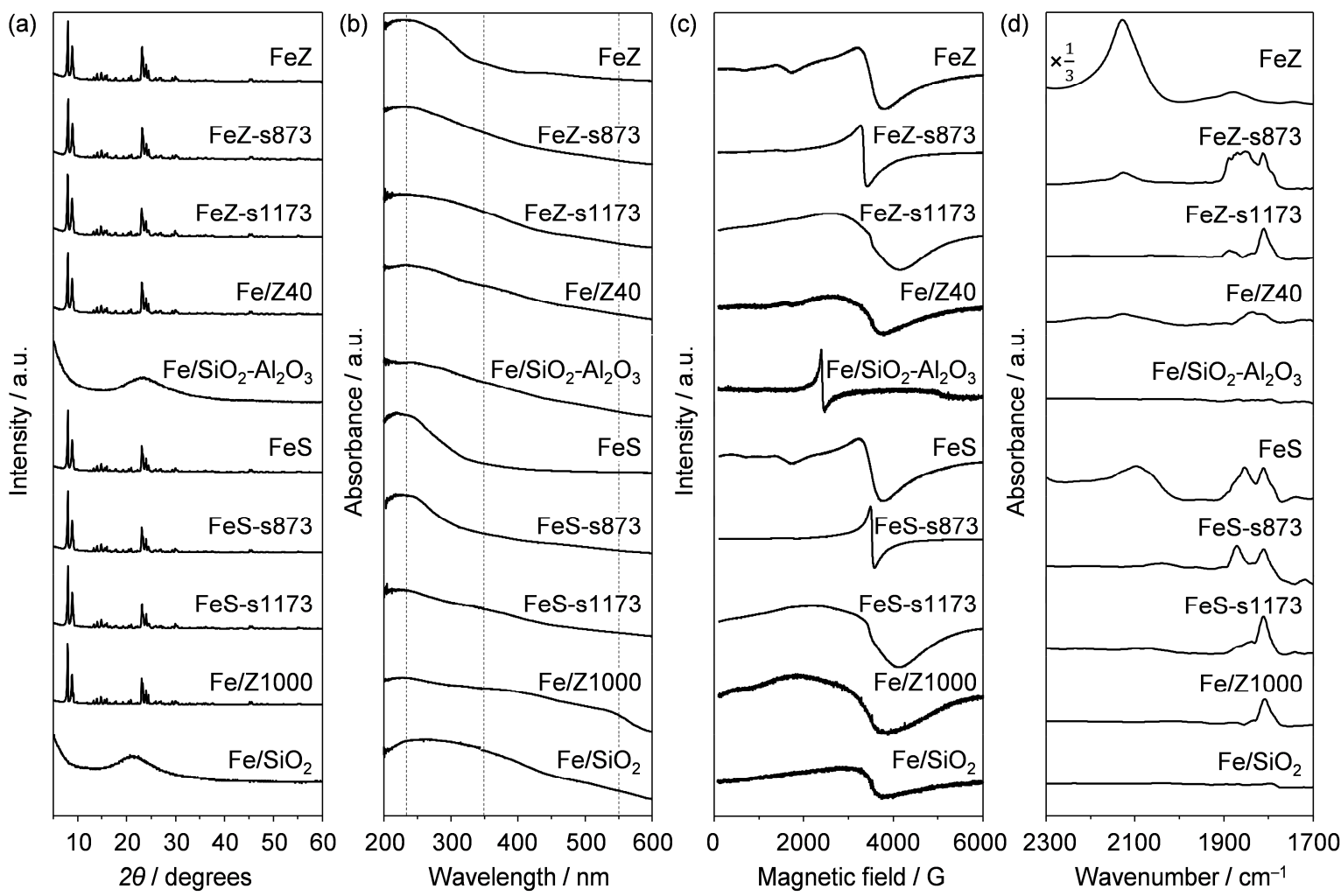

Figure 1. (a) XRD patterns, (b) UV-Vis spectra, (c) EPR spectra, and (d) DRIFT spectra of adsorbed NO of the iron-containing catalysts. 
(a)
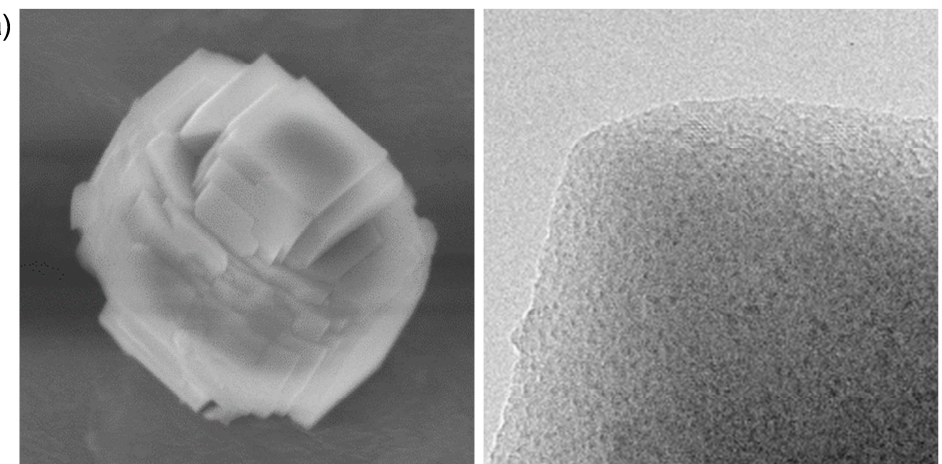

(b)
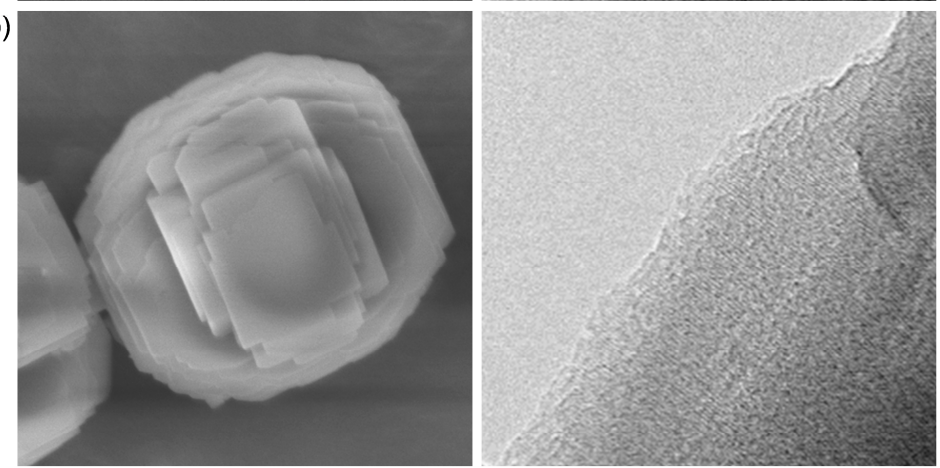

(c)
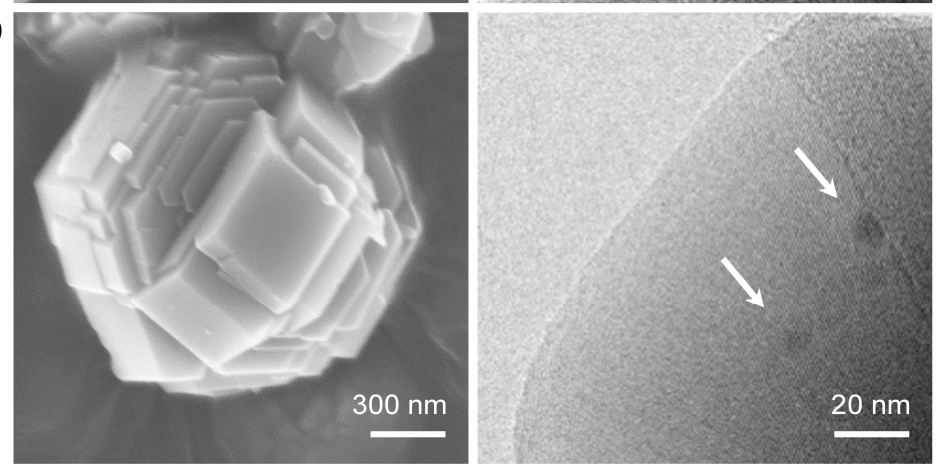

Figure 2. SEM (left) and TEM (right) images of (a) FeS, (b) FeS-s873, and (c) FeS-s1173. The scale bars apply to all of the micrographs obtained via the same technique. 
Figure 3. (a) UV-Vis spectra and (b) DRIFT spectra of adsorbed NO of the impregnated Fe/S catalysts with different iron loadings. 


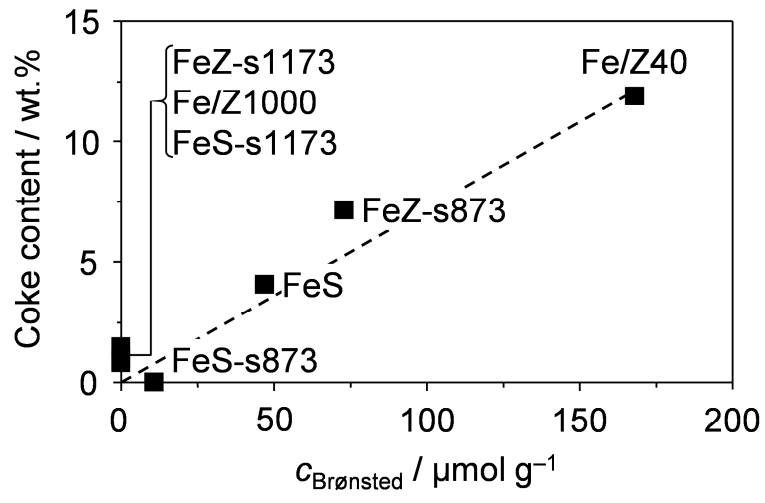

Figure 4. Coke content in selected zeolite catalysts after glycerol oxidation as a function of the concentration of Brønsted-acid sites in the samples. 

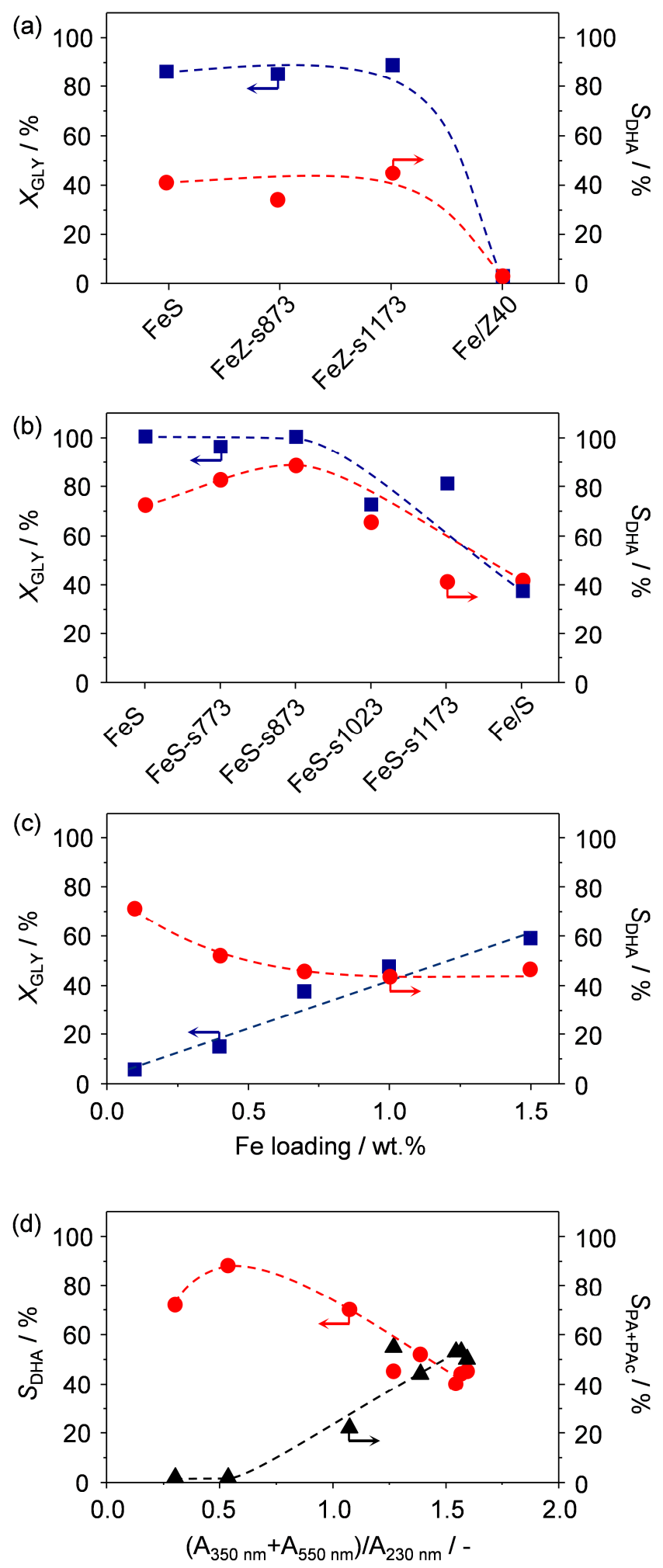

Figure 5. Performance of (a) FeZ and (b) FeS steamed at different temperatures in glycerol oxidation. (c) Glycerol conversion and dihydroxyacetone selectivity over the Fe/S catalysts with different iron loading. (d) Dihydroxyacetone selectivity and cumulative selectivity to pyruvaldehyde (PA) and pyruvic acid (PAc) over $\mathrm{FeS}$ and $\mathrm{Fe} / \mathrm{S}$ as a function of the 
proportion of medium/large iron particles and isolated iron sites/small iron clusters as determined by UV-Vis spectroscopy.
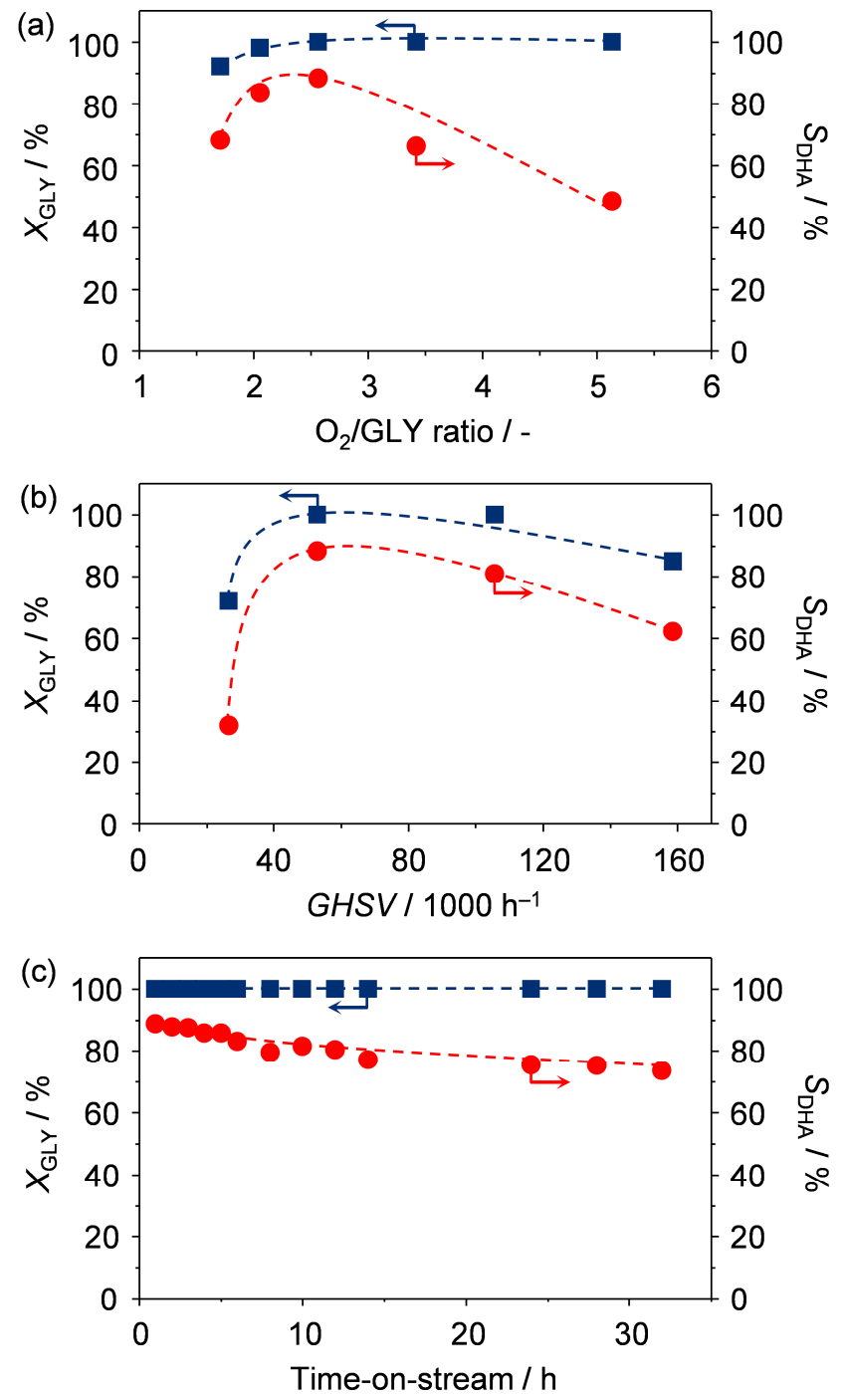

Figure 6. Performance FeS-s873 in the oxidation of glycerol to dihydroxyacetone at $623 \mathrm{~K}$ as a function of the (a) feed $\mathrm{O}_{2} / \mathrm{GLY}$ ratio, (b) reactant $G H S V$, and (c) time-on-stream. 